BULLETIN Bulletin hispanique

HISPANIQUE Université Michel de Montaigne Bordeaux

119-2 | 2017

La Égloga renacentista en el Reino de Nápoles

\title{
Dido y Fortunata
}

Dos historias de amantes

\section{Pilar Hualde Pascual}

\section{(2) OpenEdition}

Journals

Edición electrónica

URL: http://journals.openedition.org/bulletinhispanique/5184

DOI: 10.4000/bulletinhispanique.5184

ISSN: 1775-3821

Editor

Presses universitaires de Bordeaux

\section{Edición impresa}

Fecha de publicación: 1 diciembre 2017

Paginación: 693-714

ISBN: 979-10-300-0218-8

ISSN: 0007-4640

\section{Referencia electrónica}

Pilar Hualde Pascual, «Dido y Fortunata», Bulletin hispanique [En línea], 119-2 | 2017, Publicado el 28 diciembre 2020, consultado el 13 enero 2021. URL: http://journals.openedition.org/bulletinhispanique/ 5184 ; DOI: https://doi.org/10.4000/bulletinhispanique.5184 


\title{
Dido y Fortunata: Dos historias de amantes ${ }^{1}$
}

\author{
Pilar Hualde Pascual \\ Universidad Autónoma de Madrid
}

Cet article a pour objet d'identifier les échos de l'épisode amoureux de Didon et Énée (chant IV du poème de Virgile) dans la construction du portrait féminin le plus achevé qu'ait composé Galdós : celui de la malheureuse Fortunata.

Mots-clés : Fortunata, Virgile, survivance, Classiques.

Nuestra propuesta en este trabajo es la detección de ecos del episodio amoroso de Dido y Eneas, narrado en el canto IV del poema virgiliano, en la construcción del máximo retrato femenino que hizo nuestro autor, el de la desdichada Fortunata.

Palabras claves: Fortunata, Virgilio, pervivencia, Clásicos.

In this work, we propose the detection of echoes of the Dido and Aeneas love episode, narrated in the IV chant of the Virgilian poem, in the construction of the most achieved feminine portrait written by Galdós, that of the unhappy Fortunata.

Keywords: Fortunata, Vergil, Survival, Classics.

1. Este trabajo se adcribe al Proyecto de Investigación HISTORIOGRAFÍA DE LA LITERATURA GRECOLATINA EN ESPAÑA 3 (HLGE3): EL "LEGADO ALFREDO ADOLFO CAMÚS” EN LA BIBLIOTECA HISTÓRICA MARQUÉS DE VALDECILLA (PROYECTO FFI2013-41976, MINISTERIO DE ECONOMÍA Y COMPETITIVIDAD). 
Galdós y los ClÁsicos: el magisterio de Alfredo Adolfo Camús

\section{Los clásicos y el humor en la formación de Galdós}

Desde hace algunas décadas se ha empezado a destacar la importancia de la formación clásica de Pérez Galdós. Esto, en buena manera, le redime de la malévola fama de prosaico y castizo que se le atribuyó y que cristalizó en la agria denominación de "don Benito el garbancero», que en su momento le diera Valle Inclán. Muy al contrario, el mundo clásico, y, en concreto, la literatura grecolatina tienen un importante peso en su obra, peso que se va haciendo más visible según se avanza cronológicamente en ella y a través del cual el escritor canario creó un complejo entramado de símbolos que sólo se pueden percibir en plenitud si son leídos en clave clásica.

El interés de Galdós por lo grecorromano se remonta a su primera juventud, precisamente a los años de su sólida formación intelectual en el colegio agustino de Las Palmas. Allí se introduce el jovencísimo Benito en el estudio de las Humanidades, en sus aulas se inicia con excelente éxito académico en las lenguas griega y latina ${ }^{2}$ y fue en este contexto donde comenzó a fraguarse su atracción por el pensamiento de griegos y romanos. Además de sus conocimientos sobre el mundo clásico, también a esta época inicial se debe hacer remontar una de las cualidades más carácteristicas del escritor: su sentido del humor. Dada su disposición natural, consolida esta faceta durante esta etapa inicial de su vida, influido por el gracejo de algunos de sus profesores de origen canario y andaluz ${ }^{3}$.

En el curso 1862-63 Benito llega a Madrid para matricularse en la flamante Universidad Central, siguiendo los deseos familiares de que obtuviera la licenciatura en Leyes. El futuro escritor se va a inscribir en las asignaturas de Historia Universal, Geografía y Literatura Latina, que constituían el preparatorio de Derecho. Es precisamente en las clases de esta última asignatura donde Galdós se encuentra con un profesor cuyo magisterio influirá, sin ningún género de dudas, en su obra y en su vida: Alfredo Adolfo Camús. No es exagerado afirmar que este Camús fue el más destacado profesor de literatura clásica del siglo XIX español, quien, desde las aulas de la Universidad Central y desde sus Cátedras del Ateneo, ilustró en las literaturas clásica y renacentista a varias generaciones de los que luegos serían nuestros prohombres del siglo XIX ${ }^{4}$. Muestra de ello es que por su magisterio pasaron escritores como Leopoldo Alas Clarín, diplomáticos como Alberto Regules y Sanz del

2. Sobre la importancia de las lenguas clásicas en su plan de estudios, sus notas excelentes en latín y castellano, y su amor temprano por griegos y latinos, Josette Blanquat, «Lecturas de juventud», Cuadernos Hispanoamericanos, 250-251, 1970-71, pp. 160-170.

3. Blanquat, op. cit., p. 171.

4. Francisco García Jurado, Alfredo Adolfo Camús, (1797-1889): humanismo en el Madrid del siglo XIX, Madrid, Ediciones Clásicas, 2002. Pilar Hualde, «Alfredo Adolfo Camús: Un intelectual entre la España isabelina y la Restauración alfonsina», Revista de Hispanismo Filosófico 22, 2017 (en prensa). 
Río, catedráticos como González Garbín o Menéndez Pelayo y políticos como Emilio Castelar, José Canalejas, o el conde de Romanones.

Tenía don Adolfo buena fama entre sus estudiantes por lo divertido de sus clases, por su gracejo y simpatía a la hora de impartir la asignatura, lo que propiciaba que la asistencia a su asignatura fuera masiva ${ }^{5}$.

Precisamente en su primer curso de estancia en Madrid, gracias a las clases del simpático erudito de origen franco-andaluz, va a encontrarse de nuevo Galdós con las dos cualidades ya vislumbradas desde el colegio canario: la huella viva del mundo clásico y el cáustico sentido del humor de que hacía gala el admirado maestro.

De esta circunstancia dejó el propio Galdós testimonio escrito, sólo tres años después de su paso por la asignatura de Literatura Latina, en un artículo periodístico publicado en La Nación el 8 de febrero de $1866^{6}$. Se trata de un testimonio fundamental para reconstruir, por una parte, el tono de las clases del jovial humanista y, por otro, la recepción que el escritor canario hizo de ellas. En la mencionada semblanza, Benito describía a su maestro diciendo que se podía «descubrir en su rostro y en sus modales los caracteres de su ingenio (...) de los más agudos y cáusticos que derraman chistes en esta tierra del humor y el chascarrillo», con lo que deja constancia del peculiar talante del catedrático.

Pero si tenían una particularidad las clases de Camús, eran sus métodos pedagógicos, motivados por la concepción que el erudito tenía de la literatura latina, a la que consideraba como un instrumento al servicio de la vida. Como destaca Galdós en su mencionado artículo, la versatilidad del maestro le hacía llevar los temas de la literatura de la antigua Roma a la sociedad del momento, hasta el punto de que entre los estudiantes de Derecho pasaba por ser un especialista en la crónica social escandalosa de los tiempos de Augusto7. $\mathrm{Y}$, ciertamente, Camús adoptaba esta actitud de manera consciente con los alumnos de preparatorio de Derecho, para que, a través de los textos latinos, pudieran ponerse en disposición de afrontar los diversos conflictos humanos a los que iban a tener que hacer frente en el ejercicio de su profesión: los derechos del individuo, la propiedad, o, lo que aquí nos será de mayor interés, el matrimonio ${ }^{8}$.

5. «De mis maestros en la Universidad, rememoro al anciano Camús, el de mayor prestigio de entonces pero ya en plena decadencia. Eran sus lecciones de las más escuchadas, para entrar en su aula era necesario formar cola. De sus palabras brotaba siempre algún fugaz destello de su ingenio de otros tiempos, y nunca faltaban en sus explicaciones notas de subido color erótico que regocijaban y hacían trepidar a su juvenil auditorio». (Conde de Romanones, Notas de una vida, Madrid, Marcial Pons, 1999, p. 15). El testimonio del Conde de Romanones es de los años previos a 1884, fecha de su licenciatura, por tanto, se refiere ya a un Camús anciano, a diferencia del profesor que conoce Galdós bastantes años antes.

6. Publicados en William Hutchinson Shoemaker, Los artículos de Galdós en «La Nación» 1865-1866, 1868 recogidos, ordenados y dados nuevamente a luz con un estudio preliminar, Madrid, Ínsula, 1972.

7. Blanquat, op. cit., p. 180.

8. Blanquat, op. cit., p. 182. 
Efectivamente, ante la universalidad de estos problemas, el maestro trasmitía a los alumnos la idea de que el hombre es en esencia el mismo, independientemente de la época en que le haya tocado vivir, dado que está sometido a las mismas pasiones y dado que éstas le plantean problemas muy parecidos, al chocar con las convenciones sociales de su momento, sea ésta la época augústea o el reinado de Isabel II.

Así, nuestro autor, al evocar las clases de la asignatura, recuerda cómo los personajes de los jóvenes presentes en las comedias de Terencio llevaban al catedrático a reflexionar con sus alumnos sobre la juventud de la sociedad del momento, la que paseaba, no por el foro romano, sino por la Carrera de San Jerónimo:

olvídase de Terencio y de la juventud romana, y se viene a nuestros días, a Madrid, y persigue al pollo en el paseo, en el teatro, en el estudio, en los amoríos; le da caza, se apodera de él y no le suelta hasta que, desplumándolo públicamente, le manifiesta en toda su debilidad, en toda su petulancia.

\section{El magisterio de los latinos y la universidad de la calle}

Aunque Galdós no ejercerá nunca el Derecho ni tendrá que mediar en los conflictos para los que pretendía preparar don Adolfo a los jóvenes aspirantes a abogado, sin embargo, de este primer curso en Madrid sacará un impagable provecho, ya que, a la vez que descubre la "vida» de la época romana en las aulas, empieza a descubrir la «vida» contemporánea en las calles de Madrid, por las que se pierde muchas veces en lugar de acudir a la Facultad de Leyes. Y será precisamente del encuentro, comparación y síntesis de ambos mundos, el romano y el madrileño, de donde saldrán algunos rasgos de sus más célebres personajes.

El propio autor nos comenta su actividad cotidiana de aquellos primeros años universitarios:

Mis horas matutinas las pasaba en la Universidad (...) Asistía yo con intercadencia a las cátedras de la Facultad de Derecho y con perseverancia a las de Filosofía y Letras (...) Pero sin faltar absolutamente a mis deberes escolares, hacia yo frecuentes novillos, movido de un recóndito afán, que llamaré higiene o meteorización del espiritu. Ello es que no podia resistir la tentación de lanzarme a las calles en busca de una cátedra y reconocimiento visual de las calles, callejuelas, angosturas, costanillas, plazuelas y rincones de esta urbe madrileña, que a mi parecer contenian copiosa materia filosófica, jurídica, canónica, económica, política y, sobre todo, literaria. (Galdós, Guia espiritual de España [en La razón de la sinrazón], Madrid, 1915, pp. 252-253).

Al igual, pues, que las calles madrileńas recién descubiertas fueron para Benito una buena cátedra de la que extraer abundante material para su novelística, el magisterio de los latinos tuvo su peso académico, sin duda, en estos mismos tiempos. Gracias al repaso que en su semblanza sobre Camús en La Nación hace Galdós de los escritores por los que sentía especial gusto su catedrático 
de literatura latina ${ }^{9}$, podemos inferir también cuáles pudieron influir más en la obra de nuestro autor: la comedia romana, con especial atención al tipo del joven y al del parásito, poetas latinos como Horacio, Ovidio, Catulo, Propercio o Marcial, que propiciaban el regocijo del maestro con la narración de la oscura historia de la hija de Augusto y su relación con el destierro del autor de los Tristia o su entusiasmo en la glosa de la figura de Lesbia y su passer muerto, y, definitivamente, Virgilio, el Virgilio campestre de Bucólicas y Geórgicas, y el Virgilio épico de la Eneida. En clara desventaja quedaban otros escritores como Lucrecio o César, sobre los que el maestro pasaba como de puntillas ${ }^{10}$.

Desde luego, se ha visto en la obra de nuestro autor la huella del pensamiento moral de autores latinos en casos como su crítica del fanatismo y de la ambición humanas, que presenta ecos de las sátiras de Juvenal y Horacio, y en su defensa de la indulgencia ${ }^{11}$, así como también abundan en sus novelas las consideraciones en torno a la oposición entre naturaleza y sociedad o las reflexiones sobre la educación ya tratadas en el teatro de Terencio, de la misma manera que los tipos del parásito o del adulescens de la comedia romana se trasladan a las calles madrileńas por mano de nuestro autor ${ }^{12}$. Asimismo, muchos de sus personajes femeninos pueden ser trasuntos decimonónicos de aquella Lesbia cuyas fechorías glosara Camús en las aulas de la Central. Pero las clases del profesor francoandaluz no se limitaban al comentario de los autores latinos, sino que, siguiendo su característica versatilidad, comparaba la obra de aquellos con la de otros eximios clásicos europeos y españoles: Shakespeare, Molière $y$, especialmente, nuestro Cervantes salpicarán los comentarios del erudito y contribuirán a convertirlos en modelos estéticos y sobre todo, referentes morales de Galdós.

De entre todos los autores latinos mencionados, tenía don Alfredo Adolfo una especial querencia por Virgilio, autor que Galdós ya conocía, incluso en lengua original, por sus estudios en Canarias, y cuyas obras poseía en esta primera época de estudiante ${ }^{13}$. El profesor consideraba a Virgilio como el exponente de

9. Cf. Shoemaker, op. cit., pp. 266-270.

10. El buen conocimiento de la historia de la literatura romana por parte del escritor canario se deja también ver en la descripción que hace de una biblioteca de clásicos latinos que poseía el conónigo de Orbajosa en su novela Doña Perfecta (1876): «Enorme estante de roble contiene una rica y escogida biblioteca, y allí está Horacio el epicúreo y sibarita, junto con el tierno Virgilio, en cuyos versos se ve palpitar y derretirse el corazón de la inflamada Dido; Ovidio el narigudo, tan sublime como obsceno y adulador, junto con Marcial, el tunante lenguaraz y conceptista; Tíbulo el apasionado, con Cicerón el grande; el severo Tito Livio, con el terrible Tácito, verdugo de los Césares; Lucrecio el panteísta; Juvenal, que con la pluma desollaba; Plauto, el que imaginó las mejores comedias de la antigüedad dando vueltas a la rueda de un molino; Séneca el filósofo, de quien se dijo que el mejor acto de su vida fue la muerte; Quintiliano el retórico; Salustio, el pícaro, que tan bien habla de la virtud; ambos Plinios, Suetonio y Varrón; en una palabra, todas las letras latinas, desde que balbucieron su primera palabra con Livio Andrónico, hasta que exhalaron su postrer suspiro con Rutilio». (Doña Perfecta, XXV, 246-247).

11. Blanquat, op. cit., p. 189.

12. Blanquat, op. cit., pp. 191-198.

13. En concreto, en la biblioteca del autor se conserva un ejemplar de la Eneida en traducción 
la culminación del desarrollo de la literatura romana ${ }^{14}$ y eso pesará en la postura estética asumida por Galdós. Pero, a pesar de que se ha señalado cómo existen en la obra galdosiana elementos bucólicos que continúan -entre otros- los del Virgilio de las Bucólicas y Geórgicas, insertos en la propuesta de nuestro autor de la vuelta al campo como remedio para los males patrios ${ }^{15}$, hasta ahora no se ha hecho referencia a la importancia de la Eneida como una de las obras latinas que, más allá de la mera recepción literaria, han configurado el pensamiento moral y estético del joven Benito y que, en definitiva, han permitido que legara para la posteridad el abigarrado universo de sus personajes.

Nuestra propuesta será, precisamente, detectar ecos del episodio amoroso de Dido y Eneas, narrado en el canto IV del poema virgiliano, en la construcción del máximo retrato femenino que hizo nuestro autor, el de la desdichada Fortunata.

\section{Leyendo a Virgilio, imaginando a Dido y Creando a Fortunata}

\section{Dido en Galdós: arquetipo del abandono}

Que Virgilio era autor fundamental en las clases de Camús queda fuera de toda duda. Que la Eneida era obra que le interesaba sobremanera, y que el canto IV era objeto de especial comentario durante el curso de Literatura Latina es algo que se puede inferir fácilmente de las palabras del incipiente escritor canario, cuando detalla las explicaciones del maestro en los siguientes términos (las negritas son nuestras):

El mar inmenso, hinchado, colérico; las naves destrozadas, los troyanos esparcidos sobre el agua (rari nantes), el dios acuático que asoma la cabeza coronada de yerbas marinas, y después de poner cara de judío, lanza el apóstrofe y la suspensión famosa Quos ego...; las intrigas de Venus, las de Amor, la amabilidad cartaginesa de Dido, la relación de los tapices, las libertades que el hijo de Citherea se tomaba en

del ilustrado liberal canario Graciliano Afonso, que tanto influyera en el colegio en que se formó nuestro autor, y que es de suponer fuera obra de referencia en sus estudios de bachillerato. Cf. Hyman Chonon Berkowitz, La biblioteca de Benito Pérez Galdós. El Museo Canario, 1951, 195-196 y Sebastián de la Nuez, La biblioteca de Benito Pérez Galdós: catálogo razonado, Ediciones del Cabildo Insular de Gran Canaria, 1990, pp. 195-196.

14. De hecho, por los programas del curso de Literatura Latina de Camús editados, se sabe que el curso terminaba con la literatura de Virgilio, lo que da cuenta de su valoración estética entre "clásicos» $\mathrm{y}$ «decadentes» y su admiración por la Edad de Oro romana y las diversas Edades de Oro de las Literaturas Europeas. Sobre su concepción de la historiografía de la Literatura Latina y sus planteamientos estéticos y su influencia en Galdós cf. Francisco García Jurado, «La historiografia de la literatura latina y su conciencia en los autores modernos: visiones divergentes del canon y la decadencia en Pérez Galdós y Huysmans», Cuadernos de filología clásica: Estudios latinos, 24, 1, 2004 , p. 115-147.

15. Ángel Ruiz Pérez, «Visión bucólica y regeneracionismo de Galdós», en Yolanda Arencibia, M. P. Escobar, R. M. Quintana (eds.), Galdós y el siglo XX. VIII Congreso internacional galdosiano. Las Palmas 2005, Las Palmas de Gran Canaria, Cabildo de Gran Canaria, 2009, pp. 123-138. 
casa de la hermana de Pigmalión; el episodio un tanto verdinegro de la cueva, la traición del hijo de Anquises, su fuga, la muerte desesperada de la Reina, su hermana Ana, la jura, las «dulces prendas» y el «neque te teneo», Jurico, Lavinia, la bajada a los infiernos, todo el poema, en fin, es objeto de un análisis detenido, lo más detenido posible, atendido el corto tiempo de un curso y la hora y media escasa de la explicación diaria. («Alfredo Adolfo Camús», La Nación, 8 de febrero de 1866).

El propio tono de la reseńa galdosiana, que recuerda al desenfadado de Camús, actualiza la situación de los amantes épicos al definir el inicio de su relación como «las libertades que (...) se tomaba» y la culminación de su pasión como «el episodio un tanto verdinegro ${ }^{16}$ de la cueva», lo que supone una puesta al día de los hechos épicos, seguramente siguiendo la chispeante explicación del profesor de latín.

Por lo demás, los términos traición y fuga no dejan lugar a duda sobre cuál es la versión de los hechos que el maestro transmitía a los discípulos acerca de la culpabilidad del elemento masculino de esta pareja.

Independientemente de que los estudiosos actuales de la literatura latina hayan indagado profundamente en la naturaleza de la relación de Dido y Eneas -no siempre llegando a las mismas conclusiones-, lo cierto es que Eneas aparece descrito con las características tradicionales del seductor ${ }^{17}$ que, habiendo hecho profesión solemne de matrimonio, manifestada, como es habitual en el mundo grecorromano, en el hecho de tomar la mano derecha de la amada, decide anteponer sus intereses personales y postergar cualquier compromiso moral contraído. A su vez, la reina cartaginesa aparece dotada de las características propias de la mujer seducida, presentes ya en la literatura griega ${ }^{18}$, como es su disposición a darlo todo por su amante y a posponer sus intereses en función de su pasión desmedida, lo que lleva como consecuencia la pérdida de su buen nombre.

De cualquier manera, para alguien formado en las letras clásicas, y especialmente latinas, la sola mención de Dido podría ser referente de abandono.

Que así era para Galdós es un hecho evidente. La muestra más palpable nos la ofrece en una novela de su última época, aquella en la que más uso explícito hace de la mitología y literatura clásicas. Se trata del Amadeo I, obra de la quinta serie de los Episodios Nacionales y, justamente, con la que nuestro escritor se interna en una búsqueda de nuevas formas narrativas, de manera paralela a su propia evolución ideológica.

16. Verdinegro: «verde oscuro». Aquí empleado irónicamente por «verde» en su acepción de la RAE: «Dicho de un cuento, de una comedia, de una poesía, etc.: Libres, indecentes, obscenos».

17. Cf. Pilar Hualde Pascual, «Las otras Ariadnas: mujeres abandonadas en la literatura clásica», Ideas de mujer. Facetas de lo femenino en la Antigüedad / coord. por Rosario López Gregoris, Luis Unceta Gómez, Alicante, Llith, 2011, pp. 131-158.

18. Bibliografía clásica al respecto es Bernard Fenik, The influence of Euripides on Vergil's Aeneid, Princeton Univ., 1960; Francesco della Corte, «Perfidus hospes», en J. Bibauw ed., Hommages à Marcel Renard, Bruselas, 1969, pp. 312-321 o Christopher Collard, «Medea and Dido», Prometheus 1975, I , pp. 131-151. 
En esta novela, cuyo tempo narrativo, por cierto, abarca parte del periodo de la historia de España en que se sitúa la acción de Fortunata y Jacinta, aparece el personaje histórico de Adela de Larra, conocida por el sobrenombre de «La dama de las patillas» por el particular peinado que solía llevar ${ }^{19}$ y que era hija, nada menos, que del malogrado escritor romántico Mariano José de Larra. Es conocido el romance que Adela mantuvo con el soberano de la casa de Saboya durante su efímero reinado espańol y que acabó, al parecer, por las exigencias económicas de la dama, que llevaron a Sagasta a expulsarla de la capital $^{20}$. En la versión novelada de nuestro autor, «la de las patillas» acude a Santander siguiendo a Amadeo, quien, con ocasión de una real excursión, se ha desplazado a la ciuda cántabra. Allí Adela contempla cómo el monarca la abandona por otra mujer, a la sazón esposa de un corresponsal británico del Times. Enviados del rey fuerzan a la hermosa a devolver las cartas íntimas enviadas por el soberano, bien mediante estipendio, bien por fuerza de la amenaza de muerte. Los celos, la desesperación y el sentimiento de engaño de Adela son enfatizados por Galdós, mediante la sustitución de su nombre precisamente por el de Dido ${ }^{21}$ (las cursivas son nuestras):

Por sus propios ojos vio Adela que entraban en la falúa el corresponsal del Times y su bella señora (...) La hermosa Dido, abandonada contra el fuero de amistad y amor, mostraba claramente su despecho y celosa furia cuando embarcó en la jardinera de dos caballos para retirarse á su gruta del Hotel del Comercio.

Aferrada locamente á esta resolución, castillo formidable de la flaqueza femenina, hizo saber al Rey lo que proyectaba. Alarma y susto en la pequeña Corte del Sardinero; mensajes, recaditos (...) Pronto se vio que la deidad irritada no cedía. Sonaron los primeros fragores del escándalo: la tempestad estaba cerca (...) Transcurrieron dos días; al tercero presentose en el Hotel del Comercio y en la estancia de la dama un caballero amigo del Rey, pidiéndole conferencia reservada. Sentóse Dido abandonada junto á la mesilla donde pasaba las horas escribiendo y rasgando cartas, e invitando al caballero á sentarse frente á ella, le preguntó el motivo de su visita.

Airada respondió la señora que quizás vendería los documentos históricos por una palinodia del Soberano, reconociendo su veleidad y poniéndole remedio (...) Por dinero no los daría nunca. Entablose una breve y agria disputa. Dido enamorada se

19. Así la describe Pérez Galdós en su novela: «Era la tal de mediana talla, bien formada y no mal constituida de carnes y anchuras (...) el rostro, tan agraciado como hermoso: tez morena, ojos expresivos, grande la boca, tan abundante el pelo, que no se contenía dentro de sus límites naturales, extendiéndose por delante de la oreja, como un rudimento suave de varoniles patillas». (Amadeo I, XX, 232-233).

20. Josep Miguel Cruz Giráldez, «Realidad y literatura en los Episodios Nacionales: el caso de "Amadeo I", Actas del Tercer Congreso Internacional de Estudios Galdosianos, 1989, Vol. 2, 1990, pp. 351-357.

21. Inmediatamente antes, en el marco de una comparación, la asemeja a Calipso, otro prototipo clásco de abandono: «Escribía cartas con febril mano, y las rasgaba en pedazos antes de concluirlas. Por no bajar al comedor se hacía servir en su habitación. Como Calipso en su gruta, ne pouvait se consoler de la partida de Ulises». Sobre los prototipos de mujeres abandonadas en la literatura clásica cf. Pilar Hualde Pascual, «Las otras Ariadnas: mujeres abandonadas en la literatura clásica», op. cit., pp. 131-158. 
defendia fieramente contra el abandono. El mensajero del Rey, hombre que iba derecho al bulto y no gustaba de inútiles parloteos, sacó del bolsillo un revólver, y poniéndolo de golpe sobre la mesa, soltó este ultimátum: «Ó me da usted las cartas, ó la mato á usted ahora mismo». (Amadeo I, XXII, 263, 264, 265)

$\mathrm{Y}$ no es el único momento que en la obra galdosiana se hace referencia explícita a la reina abandonada por Eneas, sino que, en otro pasaje de tono metaliterario, nuestro autor, haciendo, una vez más, gala de su agudo ingenio y sentido del humor, al referirse irónicamente a una novela romántica, la relaciona con «las historias de griegos y romanos» -es decir, La Eneida- y denomina a Werther como «Dido macho»:

No puedes tener idea de cómo está esa criatura. En mi casa no se oyen más que suspiros, y con las lágrimas que unos ojitos negros han derramado estos días se podía haber hecho otro estanque del Retiro. Sorprendila ayer desenvainando el puñal que conserva como recuerdo de su padre. ¡Ay! qué susto. Te aseguro que si no llego a tiempo, tenemos en casa una degollina, un suicidio, una de esas gracias que mi sobrina ha leído en las historias de griegos y romanos, y que ahora las novelas sentimentales tratan de poner en moda. ¿Has leído el Werther? Es un Dido macho que se mata por amor. (El Grande Oriente, XVI, 334)

Parece, pues, claro que en el imaginario galdosiano, como es previsible en alguien que ha estudiado en su juventud la obra de griegos y latinos, el episodio de las relaciones de Dido y Eneas en la Eneida constituya el paradigma de la historia de amor truncada por el abandono del amante ${ }^{22}$.

A partir de estas observaciones, nuestra propuesta es que Galdós utilizó la figura de Dido como prototipo del abandono en la compleja construcción del sin par personaje de Fortunata. Ciertamente, son inmensas las diferencias entre la ilustre reina viuda de Siqueo, que construye una ciudad lejos de su Tiro natal, y Fortunata, una mujer del pueblo -que, por no tener, no tiene ni apellido- no muy inteligente, y vapuleada por la vida hasta el extremo de verse abocada a la prostitución. Sin embargo, ambas comparten, sin duda, su anteposición del amor a cualquier deber personal y el haber sido objeto de abandono por parte de sus respectivos amantes, llevándolas con ello al más desgraciado de los destinos.

22. Ejemplo paródico de cómo en la formación en letras latinas el canto IV de la Eneida se tiene por prototipo de historia de amor, lo da el propio Galdós en Zaragoza, cuando la madre del joven Agustín sueña con que éste sea sacerdote y atribuye el recitado de los encendidos versos virgilianos a teológicos latines. La respuesta de Gabriel Araceli, inventando la figura de «fray Virgilio» es de gran comicidad: «iGeneral ha dicho Vd.! - exclamó con sorpresa-. Mi hijo cantará misa en cuanto se acabe el sitio, pues ya sabe Vd. que para eso le hemos criado. Dios y la Virgen del Pilar le saquen en bien de esta guerra, que lo demás irá por sus pasos contados. Los padres del Seminario me han asegurado que veré a mi hijo con su mitra en la cabeza y su báculo en la mano (...) Yo me embobo cuando le oigo recitar una cosa larga, muy larga, toda en latín por supuesto, y que debe de ser algo de nuestro divino Señor Jesucristo y el amor que tiene a su Iglesia, porque hay mucho de amorem y de formosa, y pulcherrima, inflammavit y otras palabrillas por el estilo. -Justamente -le respondí-, y se me figura que lo que recita es el libro cuarto de una obra eclesiástica, que llaman la Eneida, que escribió un tal Fray Virgilio de la orden de Predicadores, y en cuya obra se habla mucho del amor que Jesucristo tiene a su Iglesia.» (Zaragoza, XII, 94-96) 
Si hemos de tener en cuenta que nuestro escritor dotaba del carácter y forma de los personajes de sus lecturas a las personas reales que conocía, hasta el punto de que éstas llegaban a serle indisociables de los personajes de ficción ${ }^{23}$, podemos suponer la elaboración del personaje de Fortunata conjugando su conocimiento -en aquellos paseos por las calles madrileñas ya mencionados- de una joven que sorbía un huevo crudo ${ }^{24}$ y la atribución a la misma de algunos de los rasgos que aparecen dibujados en la reina cartaginesa por mano de Virgilio.

Estos rasgos serían, básicamente: la desgracia que comparten la infelix Dido y «la pobre Fortunata», el concepto personal del matrimonio que reivindican ambos personajes, con la consiguiente desaprobación moral y social, y el deseo del hijo como consuelo del abandono del amante y elemento que legitima la unión.

\section{La desgracia de amar sin medida: infelix Dido y "la pobre Fortunata". Uso y función de los nombres clásicos en la obra de Galdós}

Es asunto de gran interés el uso de la onomástica en la obra de Pérez Galdós. $\mathrm{Y}$, en nuestro caso, resulta particularmente atractivo el estudio de la función que cumplen los nombres clásicos grecolatinos cuando se atribuyen a un personaje, ya como nombre real, ya como apelativo o apodo ${ }^{25}$.

En la obra cumbre de Galdós, Fortunata y Jacinta, podemos detectar al menos tres usos de los nombres propios:

Uso simbólico, que puede remitir a prototipos, a veces con referencias históricas: Juan Santa Cruz remite al mito de Don Juan, tan del gusto de Galdós, y cuya lectura de la versión francesa de Molière ha sido constatada ${ }^{26}$. Juan Santa Cruz, será, pues, el prototipo - y a veces caricatura - del seductor ${ }^{27}$.

Uso paródico: Respecto al mundo clásico, se concreta en la atribución de nombres de las grandes figuras de la Antigüedad a las más miserables figuras de individuos del momento, consiguiendo con ello un efecto carnavalesco.

23. Cf. Renée Schimmel, «Algunos aspectos de la técnica de Galdós en la creación de Fortunata", Archivum: Revista de la Facultad de Filologia, 7, 1957, 77-78; Berkowitz, Pérez Galdós. Spanish Liberal Crusader (1843-1920), The Wisconsin University Press, 1948, p. 23.

24. Así aparece ante el lector la figura de Fortunata por primera vez en el texto. Al parecer, Galdós conoció de esa mima manera a una joven madrileña con la que tuvo una relación íntima. Cf. Schimmel, op. cit., p. 78. Sobre el huevo y su simbología, cf. infra nota 35.

25. En este momento elaboramos un trabajo más amplio sobre el uso y función de los nombres cláscicos en la obra de Galdós. Nos ha sido de gran utilidad el estudio de Trinis Antonietta Messina Fajardo, «Nombres y símbolos en Marianela de Benito Pérez Galdós», Castilla. Estudios de Literatura, 1 2010, pp. 72-90.

26. Cf. Blanquat, op. cit., p. 201.

27. Del temprano interés de Benito por el mito de don Juan da cuenta el hecho de que entre sus libros se guarde una comedia, representada en Madrid en 1865, que ridiculiza a un descendiente de don Juan, cf. Blanquat, op. cit., p. 194. Cf. José Schraibman, «Una parodia de una parodia: Juanito Santa Cruz y Moreno Isla», Revista de filología de la Universidad de La Laguna, 1, 1982, pp. 7-12. 
En Fortunata y Jacinta podemos destacar los siguientes casos: El analfabeto tío de Fortunata, apodado Platón ${ }^{28}$, "José Izquierdo, a quien se da el sobrenombre porque comía en un plato como un barreño", al que se define en la novela como "el animal más grande que en mi vida he visto" y del que el propio personaje decía «soy pior que una caballería; soy más tonto que un cerrojo; no sirvo absolutamente para nada", pero que nos hace referencia al filósofo ateniense, para provocar la hilaridad del lector, hasta el punto de aplicarle el adjetivo «platónico»: «en los tiempos a que me refiero, el descrédito era tal que la propia vanidad platónica estaba ya por los suelos». A un joven crítico literario cuya actividad no le proporcionaba medios suficientes para vivir se le denomina Aristarco, con referencia paródica a Aristarco de Samotracia, primer «crítico» de Homero: «viendo pasar la sombra melancólica del aburrido Aristarco». Y, finalmente, a la vulgar querida del personaje de Juan Pablo Rubín, tránsfuga político y pretendiente a la gobernación de una provincia de tercera clase, la denomina por el nombre de la culta Aspasia, la amante milesia de Pericles, el padre de la democracia ateniense. En efecto, Refugio, de la que se dice que «se daba mucho lustre, tomando aires de señora, alardeando de expresarse con agudeza y de decir gracias que los demás estaban en obligación de reír», pretende pasar por culta e ingeniosa sin serlo, hasta el punto de que su amante, en ocasiones, se avergüenza de su presencia: «Feijoo no la había visto nunca, ni el filósofo de café acostumbraba a presentarse en público en compañía de aquella Aspasia, por cuya razón quedose Rubín un tanto cortado al ver a su amigo".

Uso irónico (ex contrariis): Está constatado, asimismo, el hecho de que Galdós da énfasis a la condición de algunos de sus personajes denominándolos mediante un nombre que denota justamente las cualidades contrarias a aquellas que realmente los caracterizan ${ }^{29}$. Esta técnica se relaciona con la reflexión galdosiana acerca de la dualidad del mundo real, de la oposición entre verdad y apariencia, representada en el empleo de los nombres. En este sentido, es significativo un párrafo de Doña Perfecta, donde el personaje de Pepe Rey se hace las siguiente reflexiones, en este caso, referidas a los topónimos:

¡Cómo abundan los nombres poéticos en estos sitios tan feos! Desde que viajo por estas tierras, me sorprende la horrible ironía de los nombres. Tal sitio que se distingue por su árido aspecto y la desolada tristeza del negro paisaje se llama Valleameno [...] y hay un barranco pedregoso y polvoriento, donde ni los cardos encuentran jugo, y, que, sin embargo, se llama Valdeflores. (Doña Perfecta, II, 11)

De esta manera creo que se debe interpretar el nombre de Fortunata, como un término irónico ex contrariis. Parece evidente que no es inocente que Fortunata -antropónimo que, por otra parte, es definido por Juan Santa

28. Sobre el interés de Galdós por la filosofía platónica y sobre cómo marca su espiritualidad sobre todo a partir de la publicación de Fortunata y Jacinta (1886-87) cf. Gustavo Correa, "Galdós y el platonismo», Agald 7, 1972, pp. 3-17.

29. Cf. Messina Fajardo, op. cit., p. 86. 
Cruz, como «un nombre muy feo», ante la insistencia de la esposa en conocer cómo se llama su rival- y término latino que significa «afortunada, favorecida por la Fortuna", dé nombre de uno de los más desgraciados personajes que salieron de la pluma del autor canario. Bajo él, creemos que se encubre el personaje virgiliano de Dido, protagonista de una de las más prototípicamente desgraciadas historias de amor.

En efecto, de las diecinueve veces que en el poema virgiliano se califica con un epíteto la figura de la reina -sea esta llamada por el nombre de Dido, por su nombre alternativo, Elisa, o simplemente calificada como «la Fenicia»nueve de ellas se hace referencia a su condición desgraciada como infelix, «desgraciada» (Verg. Aen. 1, 749; 4, 68; 4, 450; 4, 596; 6, 456; 4, 529; 5, 3); misserrima, «desgraciadísima» (4, 117); miserae, "pobre, desdichada» (4, 718), mientras que el resto hace referencia a su condición de enamorada: amans, «enamorada» $(4,101)$; a diversos aspectos de su belleza física o moral: pulcherrima, "hermosísima» $(1,496 ; 4,60)$, candida, «blanca» (5, 571); optuma, "excelente» $(4,291)$ y a su condición de fenicia: Sidonia (1, 446; 1, 613; 9 , 266; 11, 74) o Phoenissa (1, 670).

De forma paralela, el personaje de Fortunata nos es presentado por primera vez por boca del seductor, en sus conversaciones con Jacinta durante el viaje de novios, en estos mismos términos: "iAquella infeliz chica...! (...) ipobre nena!» (I, V, 2, 130). A lo largo de los días que dura la intermitente confesión de sus amores, Santa Cruz insistirá en las referencias a su antigua amante poniendo el énfasis en su desgraciada condición. Así, en la revelación final que, movido por el alcohol, pronuncia entre sollozos, llega a su máxima expresión la ironía trágica galdosiana cuando el propio lamento se convierte en un oxímoron: «Pobre Fortunata, pobre Pitusa (...)» (I, V, 5, 162). A lo largo de toda la obra siguen siendo frecuentes las expresiones que califican a Fortunata como infeliz, degraciada, o, utilizando la propia etimología de su nombre, como infortunada, y siempre se liga esta condición con su enamoramiento y con las consecuencias que éste conlleva para su persona y su honra. Dichos calificativos aparecen en boca de distintos personajes. Tal es el caso en que el propio narrador la denomina como «infortunada», justo en el momento en que Fortunata, al día siguiente de su matrimonio con Rubín, pasa por el trance de caer nuevamente en brazos de Juan Santa Cruz:

En aquel acto, todo lo que constituye la entidad moral había desaparecido con total eclipse del alma de la infortunada mujer; no había más que el impulso físico, y lo poco que de espiritual había en ello, engañábase a sí mismo creyéndose simple curiosidad. (Fortunata y Jacinta, Parte Segunda, VII, IV, 381)

En numerosas ocasiones se la califica de «infeliz joven» o «infeliz mujer», y, por boca de Santa Cruz - con la ironía que supone que sus palabras sean una estratagema para calmar los celos de su esposa- se dice «Mujer tan desgraciada no creo que haya nacido" (Parte Tercera, II, III, 74). Finalmente, incluso la propia protagonista se considera a sí misma «la persona más desgraciada del mundo, no por culpa suya, sino por disposición superior» (Parte Segunda,VII, XI, 436). 
Como la fenicia infelix Dido la infortunada Fortunata llegará a la destrucción y a la muerte por ligar su vida a una sola persona, a su ingrato amante que se convertirá, en definitiva, como atinadamente le dice Maximiliano Rubín, en su verdugo.

\section{El concepto personal del matrimonio. El tema de la honra y la palabra dada. Recriminación social del amancebamiento y del adulterio.}

Una de las más extraordinarias coincidencias entre la figura mítica de la reina tiria y la de la joven prostituta madrileña es la obstinación de ambas en considerar que su relación con el amante es equivalente a un matrimonio legítimo. En efecto, Dido, tras el episodio en que se refugia junto con Eneas en una cueva donde ambos obedecen a los impulsos de su pasión, siempre llamará matrimonio al vínculo que la une con su amante.

Este particular ha dado como fruto bibliografía abundante que pretende explicar la situación dentro del propio contexto del poema ${ }^{30}$, analizando el nivel de compromiso que el héroe troyano ha contraído con la reina de Cartago.

No obstante, la voz del narrador épico no deja lugar a dudas sobre el juicio moral que le merece el real idilio: se trata de turpis cupido "pasión vergonzosa», a la vez que juzga el uso interesado que Dido hace del término «matrimonio» como un deseo de ocultar su manifiesta culpa.

speluncam Dido dux et Troianus eandem/deueniunt. (....) neque enim specie famaue mouetur/ nec iam furtiuum Dido meditatur amorem:/coniugium uocat, hoc praetexit nomine culpam. (Verg. Aen. IV, 165-172)

Llegan a la misma cueva Dido y el caudillo troyano....... Dido ya no le inquietan las apariencias ni le preocupa su reputación, ni considera el suyo amor furtivo. Lo llama matrimonio. Con este término intenta encubrir su culpa.

nunc hiemem inter se luxu, quam longa, fouerel regnorum immemores turpique cupidine captos... (Verg. Aen IV, 193-194).

pasan juntos el invierno, tan largo como fuera, en cálida molicie, olvidados de sus reinos, presos de su vergonzosa pasión...

Pero la crítica moral no será privativa de la voz del narrador. El amante, siguiendo los esquemas que configuran la figura del seductor desde la propia literatura griega, va a desvincularse del compromiso moral contraído y va a hacer valer, por medio de razonados argumentos, la prioridad que tiene su

30. Bibliografía clásica sobre la relación de Dido y Eneas y los motivos de su separación en Antonio Ruiz de Elvira, «Dido y Eneas», Cuadernos de Filología Clásica 24, 1990, pp. 77- 98 y Dulce Estefanía Álvarez, «Dido: Historia de un abandono», Cuadernos de Filología Clásica. Estudios Latinos 8, 1995, pp. 89-110. Enormemente clarificador me ha resultado el reciente trabajo de Manuel López Muñoz, "Fida Dido Aenas perfidus», en Rodríguez López, Rosalía Bravo Bosch, María José (eds.), MVLIER. Algunas historias e instituciones de Derecho Romano, Madrid, Dykinson, 2013. 
misión política con respecto a su relación amorosa, cuya naturaleza espuria no deja de resaltar ante las exaltadas palabras de la que ya, más que reina, sólo es una pobre mujer que suplica no ser abandonada. Si la fenicia hace alusión a la mano derecha - un modo de recordar la palabra dada, pues era la mano que se tomaba en los juramentos solemnes- y a su «boda comenzada»- una manera de expresar que la palabra de matrimonio podría considerarse como el inicio de una unión legal -el héroe troyano le recuerda, en un gesto de crueldad manifiesta, que su unión nunca tuvo tal carácter, ni hubo intención alguna de establecer un vínculo solemne, sancionado en pública ceremonia -de ahí su alusión a las teas nupciales (taedas) - enlace que los dioses bendicen y los hombres reconocen:

mene fugis? per ego has lacrimas dextramque tuam tel (quando aliud mihi iam miserae nibil ipsa reliqui),/per conubia nostra, per inceptos hymenaeos, /si bene quid de te merui, fuit aut tibi quicquam/dulce meum,/miserere domus labentis et istam,/oro, si quis adhuc precibus locus, exue mentem. (Verg. Aen. IV, 314-319)

Dido: ¿¿Huyes de mí? Por estas lágrimas, por tu mano derecha, te lo pido, (pues, pobre de mí, nada más ya me queda), por nuestro enlace, por nuestra boda comenzada, si he merecido alguna gratitud de ti, o te ha sido dulce alguna cosa mía, ten piedad de una casa que se derrumba y si existe aún lugar para la súplica, te lo ruego, aparta de ti esa idea.

ego te, quae plurima fando/ enumerare uales, numquam, regina, negabol promeritam, nec me meminisse pigebit Elissae / (....) Pro re pauca loquar. neque ego hanc abscondere furtolsperaui (ne finge) fugam, nec coniugis umquam/ praetendi taedas aut haec in foedera ueni./ (...) Italiam Lyciae iussere capessere sortes; /hic amor, haec patria est. si te Karthaginis arces/Phoenissam Libycaeque aspectus detinet urbis, /quae tandem Ausonia Teucros considere terral inuidia est? Et nos fas extera querere regna. (Aen. IV 333-349)

Eneas: Yo nunca negaré, reina, que te debo gratitud por los muchos favores que me has hecho y que tú misma puedes enumerar, ni me pesará recordar a Elisa (...) Poco voy a decir de mi actuación. Yo, -no fabules-, ni pretendía esconderte esta huída con pretextos, ni te ofrecí jamás las antorchas del matrimonio, ni de tal te di palabra (...) Los oráculos Licios me ordenan dirigirme a Italia. Ese es mi amor, esa es mi patria. Si a ti, como fenicia, te fascinan las torres de Cartago y la belleza de la ciudad Líbica.(....) También para nosotros es lícito buscar un reino extranjero.

Como en el poema romano, en la trama amorosa desarrollada en Fortunata y Jacinta subyace el tema de la palabra de matrimonio. Juan Santa Cruz ha conocido a Fortunata y con intención de que la muchacha se le entregue le ha dado palabra de casamiento ${ }^{31}$, pero sin porpósito alguno de cumplirla.

31. El tema de la palabra de casamiento también es tratado de forma irónica por Galdós, quien, por boca de Jacinta hace una referencia metaliteraria a su uso en el teatro y en la ópera: "Aunque Jacinta no conocía personalmente a ninguna víctima de las palabras de casamiento, tenía una clara idea de estos pactos diabólicos por lo que de ellos había visto en los dramas, en las piezas cortas y aun en las óperas, presentados como recurso teatral, unas veces para hacer llorar al público y otras para hacerle reír». (Parte Primera,V, II, 132-133) 
-Y a renglón seguido la consabida palabrita de casamiento -dijo mirándole de lleno y observándole indeciso en la respuesta.(.....) Sí, la palabra de casamiento con reserva mental de no cumplirla, una burla, una estafa, una villanía. ¡Qué hombres!... Luego dicen... ¿Y esa tonta no te sacó los ojos cuando se vio chasqueada?... Si hubiera sido yo...» (Fortunata y Jacinta, Parte Primera, V, II, 133)

El personaje de Fortunata expresará una convicción idéntica a la de la reina tiria a lo largo de toda la novela, en el sentido de que creerá que la palabra de matrimonio dada por Juan equivale en el ámbito moral a un matrimonio solemne y así lo mantendrá hasta el propio lecho de muerte:

(...)A mi me habia dado palabra de casamiento (...) como esta es luz (...) Y me la había dado antes de casarse (...) Y yo había tenido un niño (... Y Y a mi me parecía que estábamos los dos atados para siempre, y que lo demás que vino después no vale (...). (Fortunata y Jacinta, Parte III, VII, II, 369)

Explícitamente se lo expresará a su propio amante, apenas dos días después de haber contraído matrimonio canónico con el desmedrado Maximiliano Rubín; pero el seductor, como Eneas, se desliga totalmente de semejante convicción, que la voz del narrador -que no necesariamente Galdós -denomina de 'satánica', dejando así constancia - como Virgilio con Dido- del reproche moral y social de la sociedad hacia la situación de la huérfana de la Cava de San Miguel.

En el mismo instante alzó la frente, y con satánica convicción, que tenía cierta hermosura por ser convicción y por ser satánica, se dejó decir estas arrogantes palabras: "Mi marido eres tú... todo lo demás... ipapas!». Elástica era la conciencia de Santa Cruz, mas no tanto que no sintiera cierto terror al oír expresión tan atrevida. Por corresponder, iba él a decir mi mujer eres tú; pero envainó su mentira, como el hombre prudente que reserva para los casos graves el uso de las armas. (Fortunata y Jacinta, Parte Segunda, VII, VI, 399)

La misma declaración se puede encontrar en las palabras que nuestra protagonista dirige a Jacinta en su fortuito encuentro con ocasión del velatorio de Mauricia la Dura, donde, ante la interrogación de la seńora de Santa Cruz acerca del tiempo que lleva de matrimonio, Fortunata le responde con el cómputo de los años que han pasado desde su primer encuentro amoroso con Juanito, sin dejar de reseñar que éste es anterior al momento en que la propia Jacinta contrajera nupcias legales.

-¿Qué tiempo lleva usted de matrimonio? Perdone mi indiscreción. -¿Yo?... murmuró la otra vacilando-. Cinco años. Yo me casé antes que usted (...) -iAntes que yo! (Fortunata y Jacinta, Parte Tercera, VI, V, 303)

Precisamente, es la misma idea que mantiene durante su «confesión» con Guillermina Pacheco, ante el escándalo de la «santa», que refleja la voz de la moral y de la Iglesia en este punto:

Mi conciencia!... esto sí que es raro... se lo cuento a usted como pasó... no se me alborotaba cuando cometía yo aquellos pecados tan refeos... Le diré a usted más, 
aunque se horrorice... mi conciencia me aprobaba... vamos al caso, me decía una cosa muy atroz, me decía que mi verdadero marido... -(...) Parecíame a mí -prosiguió la penitente sin poder contener la efusión de su sinceridad-, que aquel hombre me pertenecía a mí y que yo no pertenecía al otro (...) -No siga usted -interrumpió la santa alarmadísima, creyendo sentir ruido en la alcoba. Es horrible. No siga usted. ¡Virgen del Carmen! Está usted muy dañada. (Fortunata y Jacinta, Parte Tercera, VII, II, 368-369)

Por lo demás, ni siquiera la religión hace que la joven adúltera se apee de su convicción, ya que considera que su unión con Santa Cruz es producto de una disposición superior:

Sí doña Bárbara, es usted mi suegra por encima de la cabeza de Cristo Nuestro Padre, y usted salte por donde quiera, pero soy la mamá de su nieto. (Fortunata y Jacinta, Parte Cuarta, VI, II, 301)

-Que asi debe ser, que asi está dispuesto -añadió la señora de Rubín, volviendo a exaltarse y a tomar la expresión del anarquista que arroja la bomba explosiva para hacer saltar a los poderes de la tierra. Es una idea mía, una idea muy perra, una idea negra como las niñas de los ojos de Satanás... y no me la puedo arrancar. (Fortunata y Jacinta, Parte Tercera, VII, III, 376)

Incluso en el momento supremo de la muerte, cuando Guillermina la conmina a renunciar a lo que ella llama «su idea», en ocasiones denominada como «idea negra»" ${ }^{32}$, la creencia de que su relación con Juan es un verdadero matrimonio, ahora sancionado por la Naturaleza con la bendición de un hijo, Fortunata no va a renunciar a su íntimo convencimiento, por mantener el cual, Galdós permite que muera inconfesa:

Ahora recuerdo que usted tenía una idea maligna, origen de muchos pecados. Es preciso arrojarla y pisotearla... Busque, rebusque bien en su espíritu y verá cómo la encuentra; es aquel disparate de que el matrimonio, cuando no hay hijos, no vale... y de que usted, por tenerlos, era la verdadera esposa de... Vamos (con extraordinaria ternura), reconozca usted que semejante idea era un error diabólico a fuerza de ser tonto, y prométame que ha de renegar de ella y que no la olvidará cuando el amigo Nones la confiese. Mire usted que si se la lleva consigo le ha de estorbar mucho por allá».

La Pitusa no expresaba nada, por lo cual su fervorosa amiga volvía al ataque con más brío y pasión. «Fortunata, hija mía, por el cariño que me tiene (...). Eso no sirve allá, como no le sirva al demonio para hacer de las suyas... Se la arranca usted, ¿sí o no? Hágalo por mí, para que yo me quede tranquila».

Fortunata volvió a tener la llamarada en sus ojos, al modo de un reflejo de iluminación cerebral, y en su cuerpo vibraciones de gozo, como si entrara alborotadamente en ella un espíritu benigno. La voluntad y la palabra reaparecieron; pero sólo fue para decir: «Soy ángel... ¿no lo ve?...”. (Fortunata y Jacinta, Parte Cuarta, VI, XIV, 416-417)

32. La llamada aquí por Fortunata «idea negra», se corresponde con la concepción natural del matrimonio, producto de la atracción física y sancionado por la existencia de hijos. Frente a ello, la joven denominará «idea blanca» a la forma consagrada expuesta en su custodia en el convento de las Micaelas, que, en el pensamiento de Forunata le aconseja seguir las normas religiosas y sociales respecto al matrimonio. 
Se puede observar que la «idea» de Fortunata, el convencimiento de que su relación con Juan es moralmente legítima, causa el rechazo religioso y moral de su entorno, manifestado en términos como «idea maligna», "error diabólico»; «pecados» o «disparate» por boca de Guillermina, e, incluso, por boca del narrador en la expresión «satánica convicción».

En cualquier caso, la sociedad recrimina la actitud de Fortunata, al igual que la voz del narrador de la Eneida, erigido en portavoz de las ideas morales del momento, recrimina a Dido. Y es que ambos personajes de ficción son concebidos en un momento de la historia en que se impone la revalorización social del matrimonio. Si durante el imperio de Augusto, época en la que se escribe la Eneida, se promulgan leyes en defensa del matrimonio y de la generación de hijos ${ }^{33}$, en época de la Restauración, el avance de la burguesía hace consolidar el valor de la familia, el matrimonio y el orden social ${ }^{34}$. Virgilio y Galdós van a reflejar en su obra esta realidad social, por lo que la actitud de ambas protagonistas contará con el rechazo de la sociedad, una sociedad que, en el momento en que tanto Dido como Fortunata se hunden ante el abandono del amado, les recuerda, con crueldad, que ya es demasiado tarde para corregir los errores. La recriminación de Dido aparece en el marco de sus propias reflexiones de arrepentimiento y la de Fortunata por boca de su tía política, doña Lupe la de los pavos, y ambas mujeres abandonadas se califican a sí mismas de infelix «triste, pobre»:

infelix Dido, nunc te facta impia tangunt? tum decuit, cum sceptra dabas. en dextra fidesque (Verg. Aen. IV, 597-598)

Pobre Dido, ¿ahora te afectan las impías acciones? Entonces debian haberte importado, cuando entregaste tu dignidad real...Ay la mano tomada y la promesa dada...

-Aguanta, que todo te lo tienes bien merecido. Ni vengas a que yo te consuele... Acudiendo con tiempo, no digo que no. Abres ahora los ojos y te encuentras horriblemente sola, sin familia, sin marido, sin mí.(...) - «No, no, no... yo no quiero estar sola, triste de mí. (...) Sí, me portaré bien; ahora sí, ahora sì.. -Ahora sí. Vaya, hija, no madrugues tanto. Tú no te acuerdas de Santa Bárbara sino cuando truena (...) -Quien no te conoce que te compre (...) No, hija, has acudido tarde... ¡Te he estado metiendo la indulgencia por los ojos, sin que tú la quisieras ver, y ahora que te ahogas, vienes a mí...! ¡Ay!, no puedo, no puedo. (Fortunata y Jacinta, Parte Cuarta, III, III, 179-180).

La sociedad y los representantes de la moral abandonan a Fortunata, censurada como Dido por su actitud opuesta a las normas del momento. No lo hace, sin embargo, así Galdós. Cuando la adúltera Fortunata le dice a Juan Santa Cruz que él es su verdadero marido, la voz de nuestro autor, que tanto ama a su personaje, asoma en la afirmación de que aquella idea matriz de Fortunata «tenía cierta hermosura por ser convicción y por ser satánica».

33. Augusto promulgó dos leyes en defensa del matrimono, la lex Iulia de maritandis ordinibus (18 a. C.) y la lex Papia Poppaea (9 a. C.).

34. Servén Díez, Carmen, «Fortunata y su época: sobre los modelos de mujer en la España de la restauración", Alicante: Biblioteca Virtual Miguel de Cervantes, 2003 (=Homenaje a Alfonso Armas Ayala, Vol. 2, 2000, pp. 731-752). 


\section{La ańoranza del hijo como consuelo por el abandono del amante y elemento que legitima la unión}

Como es evidente, si hay un tema primordial en Fortunata y Jacinta es el de la maternidad. Desde la maternidad deseada y no lograda por Jacinta, hasta ambas maternidades ilegítimas de Fortunata, pasando por episodios simbólicos que ilustran sobre el conflicto de la separación del hijo de la madre - con el que concluirá la obra - como aquél en que Mauricia la Dura, en pleno delirio etílico, pretende sacar la hostia consagrada del sagrario para reunir a Jesús niño con su madre ${ }^{35}$, el tema de la sucesión es el catalizador de la novela.

Asimismo, aunque de forma larvada, es posible vislumbrar el tema de la maternidad en la epopeya virgiliana. Como es bien sabido, la noble sidonia es una joven viuda que no ha tenido hijos de la unión con el rey tirio Siqueo. Sin embargo, sus ansias maternales se sugieren sutilmente en el poema. La estratagema de Venus para conseguir que Dido se enamore de Eneas consistirá en hacer que Cupido tome la forma del niño Ascanio, hijo del héroe troyano, y por medio de la fascinación maternal que la reina siente por el hijo se iniciará secundariamente su pasión erótica por el padre

Tu faciem illius noctem non amplius unam/falle dolo, et notos pueri puer indue voltus, /ut, cum te gremio accipiet laetissima Dido/regalis inter mensas laticemque Lyaeum, / cum dabit amplexus atque oscula dulcia figet,/occultum inspires ignem fallasque veneno. (Verg. Aen. I, 683-688)

Tú camúflate con engaños, no más de una noche, y, hecho nińo, adopta el conocido aspecto de la criatura, para que, cuando la entusiasmada Dido te acoja en su regazo en medio de los convites regios y el licor de Lieo, cuando te abrace y te dé dulces besos, le infundas un oculto fuego y le inocules tu veneno.

El sentimiento que posee a la reina nada más ver al infante se describe con el verbo incoativo ardesco, «arder, inflamarse» - utilizado frecuentemente en las metaforas conceptuales referidas al deseo sexual -que da cuenta de la fuerza de su impulso maternal, que incluso la llevará a a acunar a Ascanio en su regazo. En este punto no creo que sea accesorio que Virgilio emplee para expresar esta última acción el verbo foveo, «calentar, abrigar», que es el empleado para definir lo que hace el ave cuando cubre a los polluelos con sus alas, e, incluso, cuando empolla el huevo ${ }^{36}$ :

35. «Sin vacilar dirigió sus pasos al altar mayor, diciendo por el camino: "Si no te voy a hacer mal ninguno, Diosecito mío; si voy a llevarte con tu mamá que está ahí fuera llorando por ti y esperando a que yo te saque... ¿¿Pero qué?... no quieres ir con tu mamaíta... Mira que te está esperando... tan guapetona, tan maja, con aquel manto todito lleno de estrellas y los pies encima del biricornio de la luna... Verás, verás, qué bien te saco yo, monín... Si te quiero mucho; ¿̨pero no me conoces?... Soy Mauricia la Dura, soy tu amiguita (...). No, no te suelto, ya no vuelves allí... ¡A casa con tu mamá...! ¿¿sí? ¿Verdad que el niño no llora y quiere ir con su mamá?...”” (Fortunata y Jacinta, Parte Segunda, VI, IX, 324-326)

36. La presencia de las aves en Fortunata y Jacinta es básica - recordemos que la familia de Fortunata se dedicaba al comercio de las mismas en el madrileńo mercado de San Miguel - y 
Praecipue infelix, pesti devota futurae,/expleri mentem nequit ardescitque tuendo/ Phoenissa, et pariter puero donisque movetur.IIlle ubi complexu Aeneae colloque pependit/ et magnum falsi implevit genitoris amorem,/reginam petit haec oculis, haec pectore totol haeret et interdum gremio fovet, inscia Dido,/insidat quantus miserae deus; at memor ille/matris Acidaliae paulatim abolere Sychaeum/ incipit, et vivo temptat praevertere amoreliam pridem resides animos desuetaque corda. (Verg. Aen. 712-722)

Y sobre todo la infeliz fenicia, destinada a próxima dolencia, no se cansa de mirarle $y$ arde de amor, y a la vez la conmueven los regalos y el nińo. Éste, una vez se hubo colgado en un abrazo del cuello de Eneas y hubo colmado el gran cariño de su supuesto padre, se dirige a la reina. Ésta clava en él sus ojos y su corazón entero y, de vez en cuando, lo abriga en su regazo. No sabe la desgraciada Dido cuán gran dios se sienta en sus rodillas. Pero él, recordando a su madre Acidalia, empieza poco a poco a destruir el recuerdo de Siqueo e intenta, por medio del amor, apoderarse de aquel espíritu, tranquilo ya desde hace tiempo, y de aquel corazón desacostumbrado a amar.

La propia Ana, hermana y desdoble moral de la reina cartaginesa, le recrimina, explícitamente, su renuncia a la maternidad, y también a los goces del amor, por permanecer fiel al recuerdo del esposo muerto:

Anna refert: o luce magis dilecta sorori,/solane perpetua maerens carpere iuuentalnec dulcis natos Veneris nec praemia noris? (Aen. IV, 31-33)

Ana le responde: ¡Oh hermana más querida que la luz! ¿acaso has de consumir tu juventud solitaria y continuamente afligida? ¿Acaso no has de conocer la dulzura de los hijos ni las recompensas del amor?

Sin embargo, una vez que Dido ha dado el paso de entregarse a Eneas, de dejar de ser univira y pasar a vivir la cálida molicie de su invierno de pasión, en el momento en que debe admitir que va a ser abandonada por la huida a

su presencia como símbolo o metáfora de maternidad y fecundidad es constante a lo largo de la obra, desde el momento que Juan conoce a Fortunata mientras ella sorbe un huevo crudo (símbolo de germen y fecundidad), pasando por la narración de cómo la Pitusa criaba a los pichones metiéndolos en su pecho («era la paloma madre de los tiernos pichoncitos»), hasta la propia alusión de la protagonista como pájara o pájara mala en la última parte de la obra. Hay bibliografía abundante que opina sobre este punto, desde Stephen Gilman, «The Birth of Fortunata», Agald 1, 1966, pp. 71-83 y Carlos Blanco Aguinaga, «On the Birth of Fortunata»; Agald, 3, 1968, pp. 13-24; pasando por Roger L. Utt, «El pájaro voló»: observaciones sobre un leitmotiv en Fortunata y Jacinta», Agald 9, 1974, pp. 37-48 y Agnes M. Gullón, «The bird motif and the introductory motif: Structure in Fortunata y Jacinta», ibid., pp. 51-75, hasta, recientemente, Leonardo Romero Tobar, «De nuevo sobre el motivo ornitológico en Fortunata y Jacinta», Agald, 40-41, 2005-2006, pp. 67-72. Desde el punto de vista de la recepción, reelaboración y uso del mundo clásico en Galdós nos ha resultado de enorme interés el trabajo de Vernon A. Chamberlin, "Aristophanes' The Birds and the ornithological tour de force in Fortunata y Jacinta, Hispanic Review 2, 1987, pp. 165-180, que demuestra cómo en la base de algunas de las imágenes ornitológicas que aparecen en la obra estaría la lectura galdosiana de Las aves de Aristófanes. Recordamos que Alfredo Adolfo Camús había dedicado algunos artículos científicos al estudio de la obra del comediógrafo ateniense. Cf. María José Barrios Castro, «Un estudio desconocido sobre Aristófanes: los artículos del catedrático Alfredo Adolfo Camús», en La historia de la literatura grecolatina en el siglo XIX español: espacio social y literario / coord. por Francisco García Jurado, 2005, págs. 267-276. 
traición de su amante, menciona el deseo de un hijo. Este posible hijo sugerido llevaría en su facciones el rostro paterno, sería un "pequeño Eneas» -un «Eneíllas», en memorable traducción de Quevedo ${ }^{37}$ - que, con la cotidianeidad de sus juegos infantiles en el patio familiar, por una parte, consolaría a la madre de la soledad y el abandono y, por otra, supondría un elemento legitimador de la unión, mencionado por la reina en un intento desesperado de invocar derechos conyugales ${ }^{38}$ :

saltem si qua mibi de te suscepta fuissetlante fugam suboles, si quis mibi paruulus aulalluderet Aeneas, qui te tamen ore referret, /non equidem omnino capta ac deserta uiderer. (Aen. IV, 327-330)

Si al menos hubiera recibido de ti algún retoño antes de tu huida, si me jugase en el patio un pequeño Eneas que te llevase de algún modo en su rostro, ciertamente no me vería del todo seducida y abandonada.

Ciertas similitudes cabe ver en la actitud de Fortunata respecto a esta valoración de la maternidad.

Ya al referirse al nacimiento del primer y malogrado Pituso, lo describe como un consuelo cuya desaparición hace que la joven caiga en la espiral del vicio:

Cuando tuve a mi niño, me consolaba con él; pero luego se me murió; y cuando reventó Juárez, como yo me pensé que ya no me querías, dije: «pues ahora me vengaré siendo todo lo mala que pueda». (Fortunata y Jacinta, Parte Segunda, VII,VII, 405).

Aún así, como se ha señalado, ese primer hijo, fruto del azar, no fue seguramente deseado ni oportuno ${ }^{39}$. Sin embargo, la obsesión del personaje durante toda la novela va a ser la persecución de una nueva maternidad. Fortunata, en repetidas ocasiones, hará referencia a su idea, la búsqueda de una descendencia que legitime su relación y que, a la vez, la consuele y, en cierta medida, sustituya al amante pérfido.

Mátate tú, si quieres, que yo tengo que vivir para criarlo, iy voy a ser tan feliz con él...! Va a ser el consuelo de mi vida. Para eso lo tengo, y para eso me lo ha dado Dios... ¿Ves cómo me salí con mi idea?... Mi hijo es una nueva vida para mí. Y entonces no habrá quien me tosa. (Fortunata y Jacinta, Parte Cuarta, III, IV, 188)

Su segundo hijo, su Juanín, como el Eneíllas evocado por Dido, lleva en su rostro las facciones del padre, de lo que dan fe verbalmente distintos personajes (Estupiñá afirma «clavado, talmente clavado (...)», Maximiliano Rubín dice «se

37. En el soneto titulado «Imitación de Virgilio en lo que dijo a Eneas queriendo dejarla», cuyo primer cuarteto dice «Si un Eneíllas viera, si un pimpollo, / sólo en el rostro tuyo, en obras mío,/no sintiera tu ausencia ni desvío/cuando fueras, no a Italia, sino al rollo».

38. Acudo aquí al clarividente estudio del profesor López Muñoz, art. cit., p. 391, quien, en su análisis jurídico, poético y retórico del enfrentamiento final entre Dido y Eneas, entiende que la peroratio de la reina cartaginesa se intensifica «insinuando a la desesperada la posibilidad de descendencia».

39. Cf. Schimmel, op. cit., p. 99. 
parece a tu verdugo (...) se parece a tu enemigo" y Segunda Izquierdo apostilla «el chico en la cara trae la casta»). La propia Fortunata lo asegura ("él será un pillo, y un ingrato; pero lo que es a su nene le tiene que querer. Como que se volverá loco con él. Y cuando vea que es su retrato vivo ¡Cristo!») y deja de ello constancia escrita en su dictado de la carta-testamento dirigida a Jacinta, por la que le hace la "fineza» de regalarle su hijo:

Escriba usted. «Para que se consuele de los tragos amargos que le hace pasar su maridillo, ahí le mando al verdadero Pituso. Este no es falso, es legítimo y natural, como usted verá en su cara. Le suplico...». (Fortunata y Jacinta, Parte Cuarta, VI, XIII,406407)

Y es que, conseguido su propósito de descendencia, la vida de Fortunata queda justificada, su felicidad es completa, no añora su relación con Santa Cruz, ni con hombre alguno y se puede decir que el fuerte sentimiento de la maternidad ha sustituido en su vida a la intensa pasión erótica que hasta tres veces la arrastró a una relación sin salida.

¡QQuia!... no señora... Yo no lo suelto (con gran excitación y desbordamientos de alegria). ¡Estoy tan contenta!... Usted me va a querer, señora ¿̨verdad? ¿¿Me querrá usted? Porque yo necesito que alguien me quiera de firme. Verá usted qué bien me voy a portar ahora. ¿Hombres?, ni mirarlos. No quiero cuentas con ninguno. Mi hijito y nada más. (Fotunata y Jacinta, Parte Cuarta, VI, VIII, 352.)

Pero, como Dido, el personaje de la madrileña está abocado a la destrucción. Cierto es que la reina tiria pone fin a una vida sin sentido por la falta de su amante, y porque se siente, realmente capta ac deserta, seducida y abandonada, sin que la ańorada presencia de un hijo pueda paliar su situación. Fortunata, por el contrario, es personaje vital, que rechaza aun el pesamiento del suicidio, porque quiere vivir para criar a su hijo, y muere, precisamente, cuando la materialización de esa deseada descendencia, la consecución de «su idea», le ha dado la dignidad de madre "del hijo de la casa» y ha conferido total justificación a su vida, llenándola de felicidad. Por eso, su muerte se hace especialmente dolorosa para el lector.

\section{REFLEXIONES FINALES}

Algunos elementos del mundo clásico parecen subyacer en el complejo proceso creativo del más acabado personaje galdosiano, Fortunata. Una prueba más, de entre las muchas que, afortunadamente, van saliendo a la luz, sobre el peso de lo grecolatino en la obra de nuestro autor. $\mathrm{Y}$ es que, hasta en los lugares más inesperados, surge en Galdós la experiencia de los clásicos, lo que hace que no se pueda calibrar en toda su dimensión la riqueza de su creación, si no se atiende a la críptica evocación que de ellos hace desde culaquier pasaje de su obra. 
No estamos hablando exactamente de tradición clásica, sino de experiencia de lector y de intelectual, experiencia vivida y recreada conforme a las particulares características de este inventor de universos que es Galdós. No es ajena a esta realidad su propia idiosincrasia, su visión irónica del mundo, que roza en ocasiones la caricatura y la parodia, y en otras -con la exquisita sensibilidad que le permite, entre otras cosas, hacer un retrato sublime de la psique femenina- eleva los caracteres de sus personajes a la altura de la tragedia.

Tanto su sentido de la ironía como su ya inicial interés por los clásicos recibieron el impulso determinante del magisterio de Alfredo Adolfo Camús, su profesor de Literatura Latina en la Universidad Central. De él obtuvo, seguramente, el joven canario no sólo su concepción historiográfica de la literatura de Roma, que le lleva a gustar especialmente de la comedia romana y de la épica virgiliana, sino su formación estética y moral, a través de las lecturas de griegos y, sobre todo, de latinos.

Virgilio, el «tierno Virgilio», si atendemos a la denominación que Galdós le da en Doña Perfecta, el «magnífico», "divino» y "sublime» Virgilio, si hemos de hacer caso a las palabras que nuestro autor pone en boca de su maestro, resultan tanto para el erudito catedrático como para su entusiasmado discípulo el punto culminante del desarrollo de la literatura de la Roma antigua, encarnación de su Edad de Oro. Esta concepción historiográfica ha llegado a impregnar la propia obra de creación galdosiana, dado que la Eneida, y muy especialmente su libro IV, se conciben como la máxima expresión literaria de una historia de amor y desamor, «en cuyos versos se ve palpitar y derretirse el corazón de la inflamada Dido». Referente universal del abandono para los estudiosos educados en el marco de las humanidades clásicas - de lo que Galdós deja cumplida constancia en los Episodios Nacionales- algunos rasgos de la desdichada reina sidonia pudieron servir a nuestro autor para construir el sin par personaje de Fortunata. La propia elección del nombre - de etimología latina- de la joven protagonista, y que define ex contrariis su desgraciada condición, en paralelo a la infelix Dido latina, abunda en esta idea. La añoranza del hijo y su función de legalización de una unión libre es también elemento compartido por ambas protagonistas.

Pero es la afirmación de Dido acerca la naturaleza matrimonial de su relación, que se reproduce de forma pertinaz en boca del personaje de la huérfana madrileña, la que da pie a Galdós para abundar en el tema que no abandonará durante toda su vida, la oposición entre naturaleza y sociedad, y así poder expresar, a través del discurso de Fortunata, sus propias ideas sobre la institución matrimonial. Esta convicción que comparten la reina de Cartago y la popular joven madrileńa las lleva a enfrentarse con una sociedad que repudia su actitud y, con ello, labran su propia destrucción. Pero también con ello logran que, más allá del suicidio de Dido en el final del libro IV de la Eneida, y más allá de la muerte por sobreparto de Fortunata en el capítulo XIV de la parte final de la obra, ambas vivan para siempre en el imaginario occidental como las más apasionadas y desdichadas amantes. 